Physical Chemistry Chemical Physics. 2013, 15:

15416-15425.

ARTICLE TYPE

doi:10.1039/C3CP51642C

\title{
Oxygen Reduction Reaction on Stepped Platinum Surfaces in Alkaline Media.
}

\author{
Ruben Rizo, Enrique Herrero* and Juan M. Feliu. \\ Received (in $X X X, X X X)$ Xth $X X X X X X X X X 20 X X$, Accepted Xth $X X X X X X X X X 20 X X$ \\ ${ }_{5}$ DOI: 10.1039/b000000x
}

The oxygen reduction reaction (ORR) in $0.1 \mathrm{M} \mathrm{NaOH}$ on platinum single crystal electrodes has been studied using hanging meniscus rotating disk electrode configuration. Basal planes and stepped surfaces with (111) and (100) terraces have been employed. The results indicate that the Pt(111) electrode has the highest electrocatalytic activity of all the studied surfaces. The addition of steps on this electrode surface 10 diminishes significantly the reactivity of the surface towards the ORR. In fact, the reactivity of the steps for the surfaces with wide terraces can be considered negligible with respect to that measured for the terrace. On the other hand, $\mathrm{Pt}(100)$ and $\mathrm{Pt}(110)$ electrodes have much lower activity than the $\operatorname{Pt}(111)$ electrode. These results have been compared with those obtained in acid media to understand the role of the $\mathrm{pH}$ and the adsorbed $\mathrm{OH}$ on the mechanism. It is proposed that the surface covered by adsorbed $\mathrm{OH}$ is 15 active for the reduction of the oxygen molecules.

\section{Introduction.}

The oxygen reduction reaction (ORR) is probably the most important electrochemical reaction due to its prominent role as a cathode reaction on fuel cells and batteries. ${ }^{1}$ The formation of the

20 final reduction product, water, requires the transfer of 4 electrons. The high number of electrons transferred in the reaction implies that the reaction mechanism is complex and several intermediates are involved in the reaction. In aqueous solutions, it is generally accepted that the reduction takes place in two overall pathways, a ${ }_{25}$ direct four-electron reduction and the "peroxide" pathway. In the latter, hydrogen peroxide appears as an intermediate. For some metals, such as $\mathrm{Hg}$, hydrogen peroxide is the major product and water is only produced at very high overpotentials. On the other hand, for platinum and other metals, water is readily produced, 30 either directly or from the decomposition of the generated hydrogen peroxide. $^{2}$ Additionally, the reaction is structure sensitive which implies that the reactants and/or intermediates are adsorbed in the surface. Thus, the complete understanding of the oxidation mechanism requires the use of well-defined surfaces, in 35 order to simplify the complexity of the reaction mechanism and to make explicit the role of surface structure and composition in the competitive adsorption processes that occur on the oxidation mechanism.

The ORR on platinum surfaces has been investigated extensively 40 and detailed models rationalizing its mechanism and complex

Instituto de Electroquímica, Universidad de Alicante, Apartado 99, E-03080 Alicante, Spain. kinetics have been previously proposed. ${ }^{3-12}$ In acidic media, there are extensive reports on how the structure of the platinum surface affects the catalytic behavior of the platinum electrode. ${ }^{11,12}$ Thus, it has been found that the electrocatalytic activity is heavily 45 influenced by the presence of strongly adsorbing anions, which mainly controls the reactivity of the surfaces. Thus, the $\operatorname{Pt}(111)$ surface is less active than the $\operatorname{Pt}(100)$ electrode in sulfuric acid solutions due to the stronger adsorption of sulfate on the $\operatorname{Pt}(111)$ electrode. ${ }^{11}$ In order to extrapolate these results to the real 50 surfaces, the effect of the presence of steps has to be studied. As a result, it has been found that the presence of steps on the electrode surface increases the catalytic activity of the surface both in perchloric and sulfuric acid solutions. These results have allowed understanding the behavior of the nanostructured 55 platinum surfaces. ${ }^{13,14}$

In comparison with acidic media, the number of studies carried out in alkaline media is scarce. ${ }^{8,15}$ The catalytic activity of these surfaces, considering half-wave potentials, decreases in the order of $\operatorname{Pt}(111)>\operatorname{Pt}(110)>\operatorname{Pt}(100)$ in alkaline media, while the order 60 in perchloric acid solution is $\operatorname{Pt}(110)>\operatorname{Pt}(111)>\operatorname{Pt}(100) .{ }^{11,12,16} \mathrm{As}$ aforementioned, the anion adsorption plays a significant role in the oxidation mechanism. However, both in perchloric acid and alkaline solutions, adsorbed $\mathrm{OH}$ is the main species in the surface in the potential window interesting for the oxygen reduction 65 reaction. Thus, it would have been expected that the reactivity order in both media was similar. However, significant differences are found.$^{8}$ In order to investigate the origin of such differences, the ORR on Pt single crystals belonging to the $[1 \overline{1} 0]$ and $[01 \overline{1}]$ zones has been studied in $0.1 \mathrm{M} \mathrm{NaOH}$. These surfaces can be 
classified in three different series, i.e., surfaces with (111) terraces separated by either monatomic (110) steps or monatomic (100) and surfaces with (100) terraces separated by monatomic (111) steps. From previous results, it is clear that the surfaces in 5 which the presence of steps results in significant changes of the reactivity are those presented here. ${ }^{11,} 12$ The analysis of the curves obtained with the hanging meniscus rotating disk (HMRD) electrode allows the determination of the reaction kinetics parameters. From these parameters, the effect of the $\mathrm{OH}$ 10 adsorption on the ORR can be understood.

\section{Experimental.}

Pt single crystal surfaces were prepared from small beads, ca. 2 $\mathrm{mm}$ in diameter, obtained by melting and subsequent slow 15 crystallization of $99.999 \%$ platinum wire. After cooling, the resulting single crystal beads were oriented, cut and polished according to Clavilier's technique. ${ }^{17}$. Prior to any experiment, the working electrodes were annealed in a gas-oxygen flame, cooled in a reductive atmosphere $\left(\mathrm{H}_{2}+\mathrm{Ar}\right)$ and quenched in ultrapure 20 water in equilibrium with this atmosphere. The electrode surface was covered by a water droplet to avoid contact to impurities during transfer to the electrochemical cell. STM results indicated that the surfaces obtained after this treatment correspond to the nominal surfaces, as previously reported. ${ }^{18,} 19$ The series of 25 surfaces used have been listed in table 1, giving the Miller indexes and the terrace-step notation by Lang, Joyner and Somorjai (LJS), which is very useful to describe the stepped surfaces according to the symmetry and width of the terrace and the symmetry of the step. ${ }^{20}$ Also, the equations to calculate the 30 step density for each series of surfaces are given.

Table 1. Notation of the different surfaces employed in the work and expression for calculating the step density. $d$ represents the atomic diameter of platinum.

\begin{tabular}{|c|c|c|c|}
\hline Zone & LJS notation & Miller indices & Step density \\
\hline \multirow{2}{*}[1\overline{1}0]{} & $\begin{array}{c}\operatorname{Pt}(\mathrm{S})[n(111) \times(111)] \equiv \\
\operatorname{Pt}(\mathrm{S})[(n-1)(111) \times(110)]\end{array}$ & $\operatorname{Pt}(n, n, n-2)$ & $\frac{2}{d \sqrt{3}\left(n-\frac{2}{3}\right)}$ \\
\hline \multirow{2}{*}[01\overline{1}]{} & $\operatorname{Pt}(\mathrm{S})[n(111) \times(100)]$ & $\operatorname{Pt}(n+1, n-1, n-1)$ & $\frac{2}{d \sqrt{3}\left(n-\frac{1}{3}\right)}$ \\
\cline { 2 - 4 } & $\operatorname{Pt}(\mathrm{S})[n(100) \times(111)]$ & $\operatorname{Pt}(2 n-1,1,1)$ & $\frac{1}{d\left(n-\frac{1}{2}\right)}$ \\
\hline
\end{tabular}

Experiments were carried out at room temperature, $22-25{ }^{\circ} \mathrm{C}$, in a classical two-compartment electrochemical cell including a platinum counter electrode and a reversible hydrogen electrode (RHE) as reference. Solutions were prepared with $\mathrm{NaOH}$ 40 (Aldrich, twice distilled) and ultrapure water from Elga. $\mathrm{H}_{2}, \mathrm{O}_{2}$ and $\mathrm{Ar}$ were also employed (N50, Air Liquide). The cleanliness of the solutions was tested by the stability of the characteristic voltammetric features of well-defined single crystal electrodes. Voltammetric curves were recorded with a signal generator (PAR 45 173), a potentiostat (eDAQ EA161) and a digital recorder (eDAQ, ED401). Oxygen reduction curves were obtained in a hanging meniscus rotating disk (HMRD) electrode configuration.
The rotation rate was controlled by a Radiometer CTV 101 apparatus. In some initial experiments, the ohmic drop was 50 corrected, as suggested in reference ${ }^{21}$. However, due to the small area of the electrodes, which leads to small reduction currents, there was no significant difference between with the results obtained without ohmic drop correction.

\section{${ }_{55}$ Results and discussion}

\section{Voltammetric characterization of the single crystal electrodes in $0.1 \mathrm{M} \mathrm{NaOH}$.}

Previous results indicate that ORR is very dependent on the nature of the adsorbed species on the electrode surface. ${ }^{11,12}$ Thus, 60 the differences in activity between sulfuric and perchloric acid solutions are mainly related to the stronger adsorption of sulfate anions with respect to adsorbed $\mathrm{OH}$. Since anion adsorption on platinum electrodes is very sensitive to the surface structure, different sequences in the activity for the single crystal electrodes 65 are found. Additionally, it has been recently reported that the $\mathrm{OH}$ coverage in perchloric acid is not affected by the presence of oxygen. ${ }^{22}$ On the other hand, the order/disorder transition in the sulfate adlayer adsorbed on $\operatorname{Pt}(111)$ electrodes is also observed during the reduction of oxygen. ${ }^{11}$ Thus, the first step in the study 70 of the ORR is the characterization of the adsorbed species on the electrode surface for the different electrodes, since they can affect the global reactivity of the surface for this reaction. Figure 1 shows some representative voltammograms of the electrodes used in this study. When compared to the well-known voltammetric 75 profiles in acid media in absence of specific adsorption, that is, in perchloric acid solution, some qualitative differences can be observed. For the $\operatorname{Pt}(111)$ electrode, the lower potential region between 0.06 and $0.40 \mathrm{~V}$ is nearly $\mathrm{pH}$ independent, but some important differences can be detected in the region between 0.60 80 and $0.90 \mathrm{~V}$ associated with $\mathrm{OH}$ adsorption. The two step process in perchloric acid, also known as the "butterfly", ${ }^{23}$ merges in an apparently single process in $0.1 \mathrm{M} \mathrm{NaOH}$ solutions almost in the same potential region. Ideally, it would have been expected that the voltammetric profiles of the electrodes in perchloric acid and ${ }_{85} \mathrm{NaOH}$ solution were the same in the RHE scale, since only adsorbed hydrogen and $\mathrm{OH}$ are involved in the voltammograms. ${ }^{24}$ However, it should be reminded that adsorption processes on the electrode surfaces are always competitive since water (or any solvent) is always present on the electrolytic media. For platinum 90 surfaces, the interactions between water and platinum are significant, as revealed by the change in the work function of $\operatorname{Pt}(111)$ surfaces upon water adsorption. ${ }^{23}$ Thus, the observed changes should be related to the significant changes in the water structure due to the $\mathrm{pH}$ changes and/or the surface electrode 95 charge. It should be stressed that the processes in the SHE scale in acid and alkaline media are separated by ca. $710 \mathrm{mV}$, which implies that the electrode charge in both media is significantly different. These changes affect not only the interaction of the water with the surface but also that of the anions with the water 100 structure, giving rise to changes in the energetics of the adsorption process, that is, changing the shape of the isotherm and thus resulting in a different voltammogram.

Additional differences are found when steps are introduced in the (111) plane. For the stepped surfaces with (110) steps, a new 
reversible pair of peaks appears at $0.26 \mathrm{~V}$, whose charge is proportional to the step density. In perchloric acid solutions, the equivalent pair of peaks is observed at $0.12 \mathrm{~V}$. The difference in the peak position between the two solutions is then $140 \mathrm{mV}$ in the ${ }_{5}$ RHE scale, which corresponds to a shift of ca. $47 \mathrm{mV}$ per $\mathrm{pH}$ unit in the SHE scale. In the absence of significant changes in the interactions between the different species, the solvent molecules and the surface, this shift would have been obtained for a reaction in which the ratio between the electrons exchanged and the 10 protons involved would be $5 / 4$. Since it is difficult to envisage such reaction, the differences in peak position should be related to changes in the interactions between the possible adsorbed species and the surface with the $\mathrm{pH}$ and/or absolute potentials. ${ }^{24}$, 25

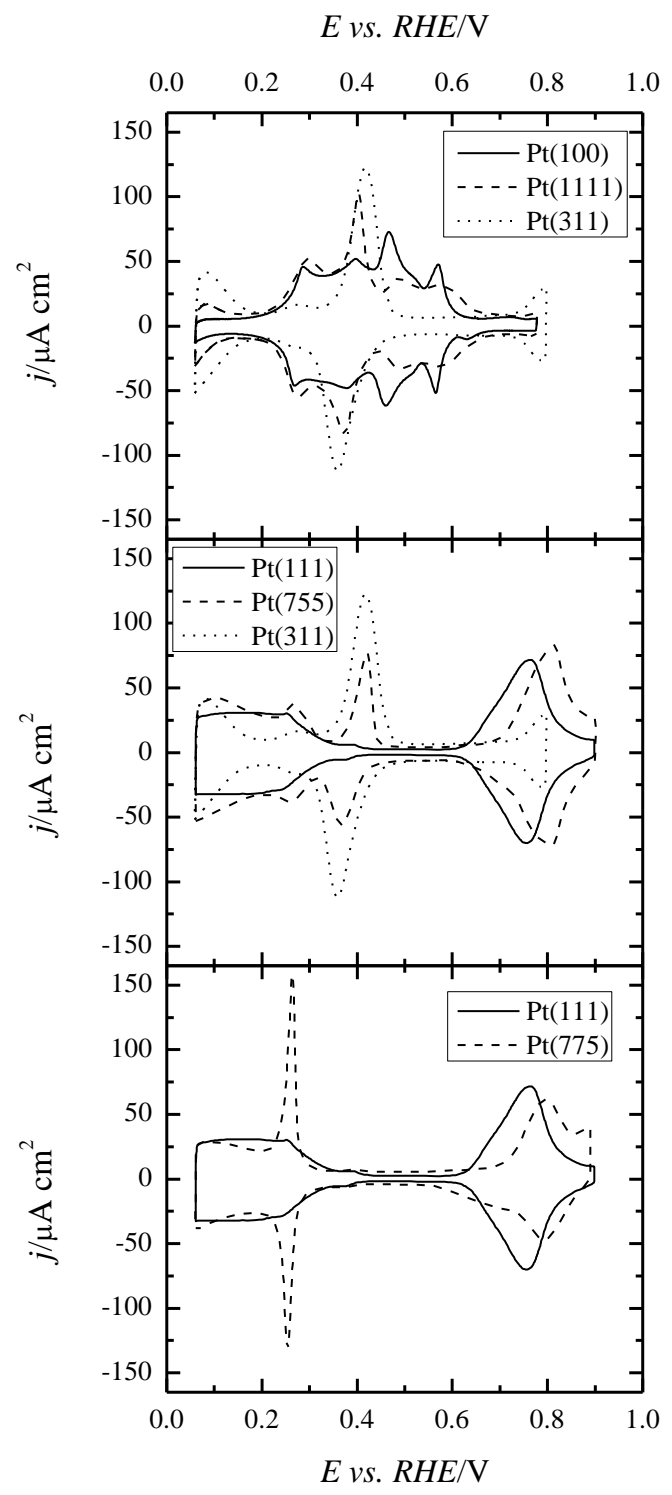

Fig. 1Voltammetric profiles of representative electrodes for the different series of stepped surfaces used in this work in $0.1 \mathrm{M} \mathrm{NaOH}$. Scan rate: 50 $\mathrm{mV} \mathrm{s}^{-1}$.
A similar situation is found when (100) steps are introduced in 20 the (111) plane. Here the peak corresponding to the (100) step sites give rise to a quasi-reversible pair of peaks at $0.37 \mathrm{~V}$ for the negative-going scan and at $0.42 \mathrm{~V}$ for the positive-going scan. In comparison, the peak in perchloric acid solutions is reversible and appears at $0.28 \mathrm{~V}$. Thus, the difference in the peak position 25 between perchloric and hydroxide media is similar to that measured for the previous series of stepped surfaces, which implies that the origin of the peak shift is similar for both step orientations, that is, the interactions between the adsorbed species/water and surface/water are $\mathrm{pH}$ dependent.

30 Regarding the nature of the species involved such peak processes for the step sites, two different possibilities can be considered. Either the peaks correspond to the competitive hydrogen/OH adsorption processes or only hydrogen adsorption/desorption processes are involved. Recent UHV studies indicate that $\mathrm{OH}$ 35 adsorption on the step site is not favored in the presence of a water layer although $\mathrm{OH}$ adsorption in the absence of water is energetically more favorable in the absence of water. ${ }^{26}$ The direct extrapolation of these results would indicate that only hydrogen adsorption is involved in the peaks. However, these results do not 40 take into consideration the presence of $\mathrm{OH}^{-}$or $\mathrm{H}^{+}$in the water at high concentrations, which can modify substantially the water structure. It should be stressed that the water structure is significantly affected by the presence of different anions, ${ }^{27,} 28$ resulting in changes in the voltammetric profiles, even at very 45 low concentrations. ${ }^{23}$ In fact, the water orientation changes in the region of the peak associated with the steps, and the rate of the water reorganization is $\mathrm{pH}$ dependent. ${ }^{29}$ Additionally, it has been recently proposed that the peaks are due to the competitive adsorption process between $\mathrm{H}$ and a mixture of $\mathrm{O}$ and $\mathrm{OH}$. The 50 ratio of $\mathrm{O}$ and $\mathrm{OH}$ adsorbed will in turn depend on the $\mathrm{pH}$, which also justifies the unexpected potential dependence of these peaks with the $\mathrm{pH}^{24}$ On the other hand, the measurements of the potential of zero total charge for the stepped surfaces indicate that the local potential of zero total charge for the step is located in 55 the middle of the peak. ${ }^{30,31}$ All these experiments suggest that the peaks correspond to the competitive adsorption process between $\mathrm{H}, \mathrm{OH}$ and possibly $\mathrm{O}$. Additionally, the observed irreversibility of the peak for the (100) step can be also associated with the adsorption process of $\mathrm{OH}$ or $\mathrm{O}$ process since hydrogen adsorption 60 is generally very fast. ${ }^{25,32,33}$

The behavior of (100) stepped surfaces has been described extensively in a previous report. ${ }^{34}$ In summary, the charge analysis indicates that the only species on the electrodes with $n>4$ below $0.4 \mathrm{~V}$ is adsorbed hydrogen on the terrace sites and $\mathrm{OH}$ on ${ }_{65}$ the step sites with a coverage of 0.5 . On the other hand, the $\mathrm{OH}$ is adsorbed both on the terrace and step sites at E>0.45 V. From the different signals appearing in the voltammogram, the peak at $0.395 \mathrm{~V}$, which increases with the step density and also becomes less reversible should be related to step processes namely $\mathrm{OH}$ 70 adsorption/desorption. Conversely, the signals at $0.295,0.465$ and $0.570 \mathrm{~V}$ should correspond to processes associated with terraces, since they diminish as the step density increases. The peak at $0.295 \mathrm{~V}$ is clearly related to the hydrogen adsorption processes whereas the peak at $0.570 \mathrm{~V}$ corresponds to $\mathrm{OH}$ adsorption on the 75 step terrace. From the measurements of the potential of zero charge of the surfaces from $\mathrm{CO}$ displacement experiments, the 
peak at $0.465 \mathrm{~V}$ should correspond to the competitive process adsorption desorption process between $\mathrm{H} / \mathrm{OH}^{34}$ It should be stressed that the potential region where hydrogen and $\mathrm{OH}$ adsorption takes place on the $\mathrm{Pt}(100)$ electrode is the same in 5 perchloric and $\mathrm{NaOH}$ media in the RHE scale, although the charge distribution is different, especially in the region where $\mathrm{OH}$ adsorption takes place (above $0.4 \mathrm{~V}$ ). Ex situ experiments confirms the presence of $\mathrm{OH}$ adsorption at $0.4 \mathrm{~V}$ on the $\mathrm{Pt}(100)$ electrode. ${ }^{35}$

\section{Effect of the surface structure on the ORR kinetics in $0.1 \mathrm{M}$} $\mathrm{NaOH}$.

Figure 2 shows the curves for the ORR on the different stepped electrodes in alkaline solutions. These curves have been obtained 15 in the hanging meniscus rotating disk configuration at $2500 \mathrm{rpm}$. In all cases, the first negative going scan is presented. It should be noted that the differences upon cycling and between positive- and negative going scans were minimal. Only the negative-going scan is presented, although the differences between the positive and 20 negative scans are minimal (less than $20 \mathrm{mV}$ at the half-wave potential). The onset for the ORR is located between 1.00 and $0.90 \mathrm{~V}$ in all cases, reaching the limiting current at ca. 0.3-0.4 V. At more negative potentials, the current diminishes due to the formation of hydrogen peroxide as final product. ${ }^{3}$ Only for the ${ }_{25} \mathrm{Pt}(100)$ and vicinal surfaces, the minimum current in the 0.06$0.30 \mathrm{~V}$ region is ca. half of the limiting current, indicating that for these electrodes the total number of electrons transferred in the mechanism is very close to 2 , and $\mathrm{H}_{2} \mathrm{O}_{2}$ (or the corresponding anion, which is the predominant species in alkaline solutions ${ }_{30} \mathrm{HO}_{2}{ }^{-}$) is almost exclusively formed. For the rest of surfaces, it should be stressed that the diminution in the current in this region is very dependent on the rotation rate. The higher the rotation rate is, the smaller the current in this region is obtained as compared to that of the limiting current. This fact implies that the reduction 35 of hydrogen peroxide is not completely inhibited in this potential region, so that a slow removal of the formed hydrogen peroxide from the interfacial region allows for a second interaction with the surface that can lead eventually to the reduction of the species to form $\mathrm{OH}^{-} .^{2}$

${ }_{40}$ When the effect of the surface structure is analyzed, it can be seen that the most active electrode in this medium is the $\operatorname{Pt}(111)$ (figure 2), since it has the lower onset for the ORR. This onset is progressively shifted to less positive potentials when steps are introduced in the (111) surface, a clear indication that the steps 45 are less active than the terrace sites. Unlike the behavior of these surfaces in acid media, the lowest activity is obtained for the electrodes with the highest step density. On the other hand, when steps are introduced in the $\operatorname{Pt}(100)$ electrode, a small shift to higher values is observed, which suggests that for this series of 50 surfaces, the steps are slightly more active than the (100) terrace sites.

In order to analyze quantitatively the data of figure 2, the kinetic current densities $\left(j_{k}\right)$, that is, the currents that would have been obtained in absence of diffusion limitations, have to be 55 calculated. Villullas et al. have published a detailed analysis of the hydrodynamic behavior of the HMRD. ${ }^{36,37}$ Thus, the standard Levich equation is modified as follows:

$$
j_{\text {lim }}=0.62 n F D^{2 / 3} v^{-1 / 6} C^{b} \omega^{1 / 2}\left[1-2 K R^{-1}(v / \omega)^{1 / 2}\right]
$$

where $F$ is the Faraday constant, $D$ is the diffusion coefficient, $v$ ${ }_{60}$ is the kinematic viscosity, $C^{b}$ is the bulk concentration of oxygen, $\omega$ is the rotation rate, $R$ is the geometric radius of the electrode and $K$ is a proportionality constant that depends on the meniscus height. However, for the meniscus conditions used in this work, negligible values of $\mathrm{K}$ are obtained, so that, the limiting diffusion ${ }_{65}$ current is well described by the Levich equation. The kinetic current density in the absence of mass transport limitation $(j \mathrm{k})$ can be obtained then using the Koutecky-Levich equation for a first order reaction:

$$
\frac{1}{j}=\frac{1}{j_{k}}+\frac{1}{0.62 n F D^{2 / 3} v^{-1 / 6} C^{b} \omega^{1 / 2}}
$$

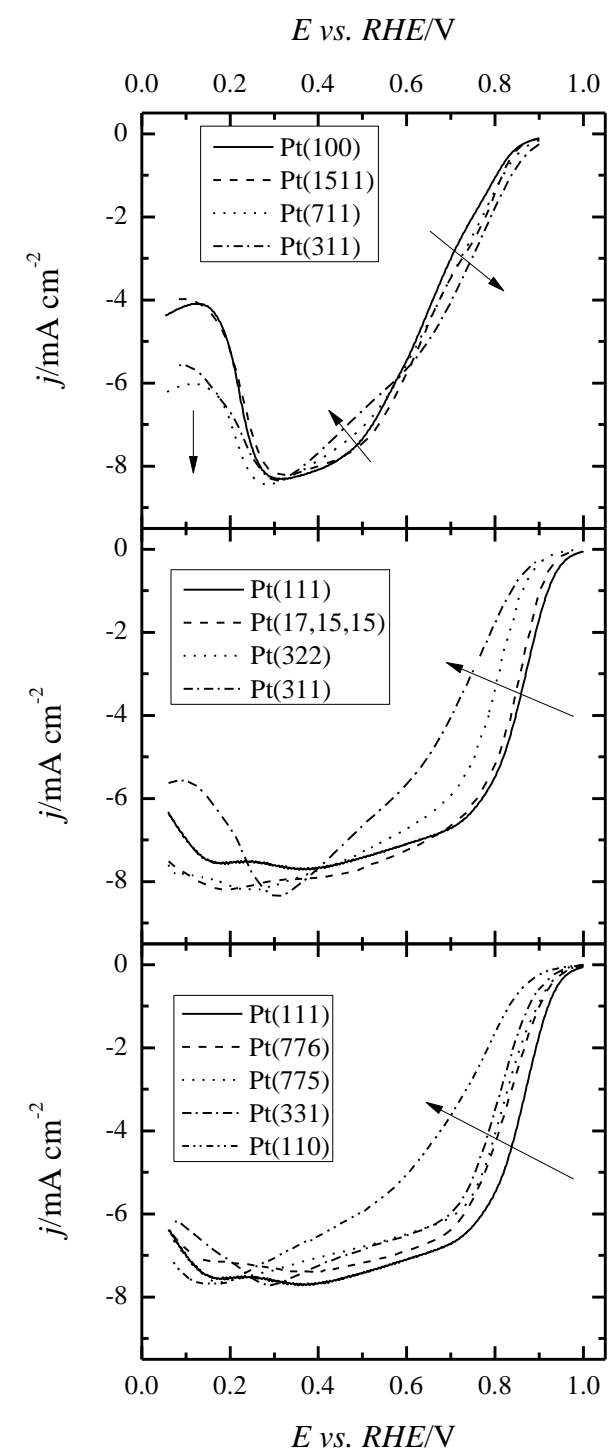

70 $\mathrm{X}$

Fig. 2. Curves for the ORR on representative electrodes for the different series of stepped surfaces used in this work in $0.1 \mathrm{M} \mathrm{NaOH}$ saturated with $\mathrm{O}_{2}$. Scan rate: $50 \mathrm{mV} \mathrm{s}^{-1}$. Rotation rate: $2500 \mathrm{rpm}$ 
By plotting the reciprocal of the current density at a given potential vs. $\omega^{-1 / 2}$, the kinetic current can be measured. Alternatively, equation (2) can also be written as:

$$
\frac{1}{j}=\frac{1}{j_{k}}+\frac{1}{j_{\text {lim }}}
$$

${ }_{5}$ Then, the kinetic current density can be calculated from a single rotation rate as:

$$
j_{k}=\frac{j}{1-j / j_{\lim }}
$$

For the $\operatorname{Pt}(111)$ electrode both procedures have been used, and the calculated kinetic currents are the same within the 10 experimental error. Since the procedure using equation (4) is simpler, this equation will be used in the following to determine the kinetic currents.

Figure 3 shows some representative curves for the ORR on the different series of electrodes. These curves follow the same trend 15 that was observed in the figure 2. From that figure, a quantitative analysis of the effect of the surface structure in the ORR in alkaline media can be made. To do that, the current at $0.80 \mathrm{~V}$ is plotted vs. the angle of the surface with the (111) plane (figure 4). As can be seen, the $\operatorname{Pt}(111)$ electrode is the most active surface 20 for the ORR in alkaline media. From this surface, the addition of steps (either with (100) or (110) symmetry) diminishes the activity and the lowest activity for the surfaces is obtained in both sides of the curve, that is, for the $\operatorname{Pt}(100)$ and $\operatorname{Pt}(110)$ basal plane electrodes. For these two surfaces, the activity of the $\operatorname{Pt}(110)$ is 25 slightly higher than that of the $\operatorname{Pt}(100)$, as has been already observed. ${ }^{8,15}$ The observed behavior is very different from that measured in perchloric acid solutions, where the maximum activity is found for the surfaces with a very high step density, i.e., $\operatorname{Pt}(331)$ and $\operatorname{Pt}(211)$. Clearly, the difference between both 30 media has to be related to the different nature of the $\mathrm{OH}$ adsorption on both media, although the voltammetric profile of the (111) electrode has similar characteristics with only subtle changes in the adsorption isotherms of $\mathrm{OH}$.

From the data presented in figure 3 , it is also possible to 35 determine the individual electrocatalytic activities of the steps and terrace sites. In order to do that, the kinetic current densities have to be plotted vs. the step density, calculated according the equations shown in table 1. Significant differences in the dependence of the activity for ORR can be observed when the ${ }_{40} \mathrm{Pt}(111)$ and $\mathrm{Pt}(100)$ vicinal surfaces are compared (figure 5). For the surfaces with (100) terraces, there is a small linear increase with step density, in a similar way to what is found for perchloric acid solutions. On the other hand, a sharp linear decrease of the activity is observed for the surfaces with wide (111) terraces, 45 although the surfaces with narrow terraces deviate from the linear trend. The effect of the steps are first related to the perturbation produced in the energy of the terrace when a step is formed. For any surface, the presence of a step creates a surface dipole due to the Smoluchoswki effect. ${ }^{38}$ However, there is a significant 50 difference between the dipole created in a (111) and a (100) terrace, due to the different electronic properties of the surfaces. Incidentally, the dipole created by the presence of a step on a $\mathrm{Au}(111)$ terrace is almost one order of magnitude higher than that measured for a vicinal $\mathrm{Au}(100)$ surfaces. ${ }^{39}$, 40 This large ${ }_{55}$ difference in the perturbation created by a step depending on the terrace symmetry explains the different behavior of the vicinal surfaces with (111) and (100) terraces. In the case (100) vicinal surfaces, the dependence of the electrocatalytic activity with the step density is also very small, ${ }^{11,41,42}$ whereas the presence of 60 steps on (111) terraces affects significantly to the reactivity of the surface. ${ }^{43,44}$ Also, significant differences are observed when adatoms are deposited on these vicinal surfaces. The large dipole created on the (111) terrace induces the deposition to the step, so that the step is completely decorated before deposition may take ${ }_{65}$ place on the step. ${ }^{45,46}$ On the other hand, preferential deposition on the step is not generally observed for the surfaces vicinal to the (100) pole. ${ }^{47}$ These differences explain why the effect of the steps on the (111) terraces is much larger than that observed on the (100) terraces. Also, the deviation observed for narrow (111)

70 terraces are assigned to the appearance of step-step interactions, which affects the overall energy of the surface. These deviations for the surfaces with narrow (111) terraces were also observed when work function changes of these surfaces ${ }^{48}$ and the pztc of the corresponding electrodes ${ }^{49}$ were analyzed.

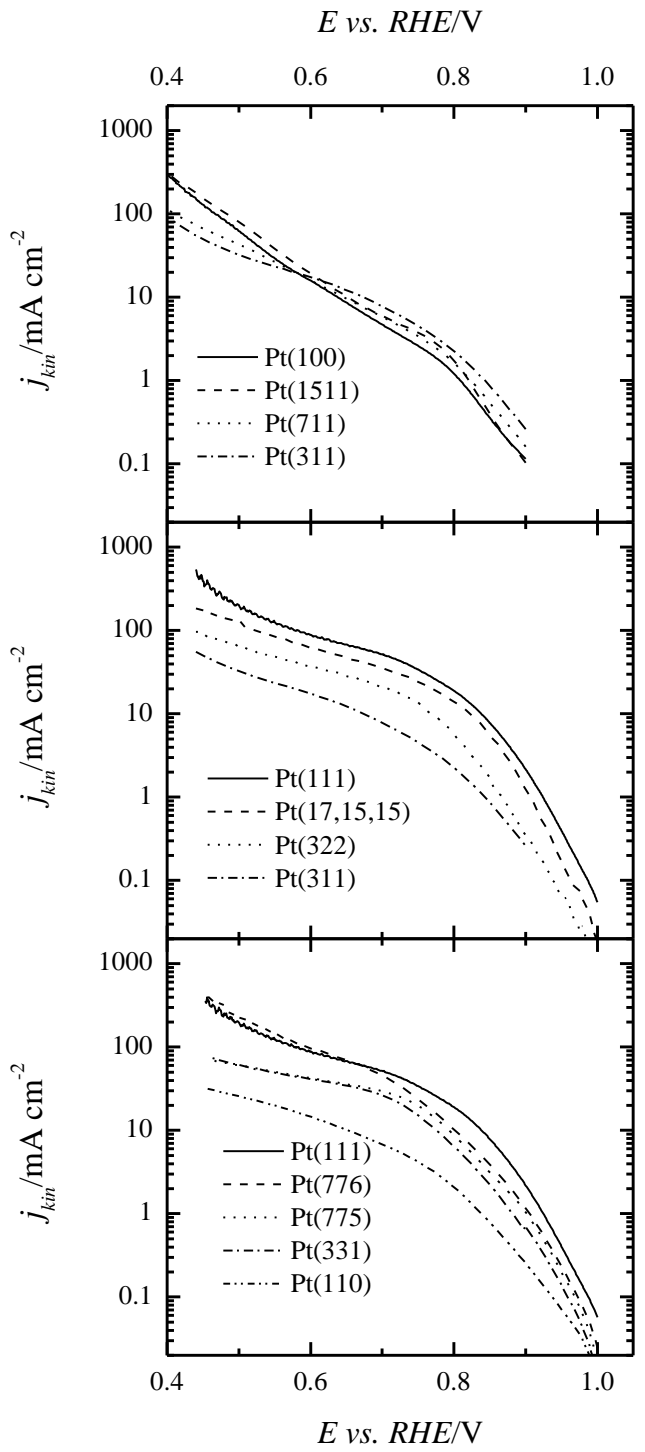


Fig. 3. Kinetic currents for the ORR on representative electrodes for the different series of stepped surfaces used in this work in $0.1 \mathrm{M} \mathrm{NaOH}$ saturated with $\mathrm{O}_{2}$.

5

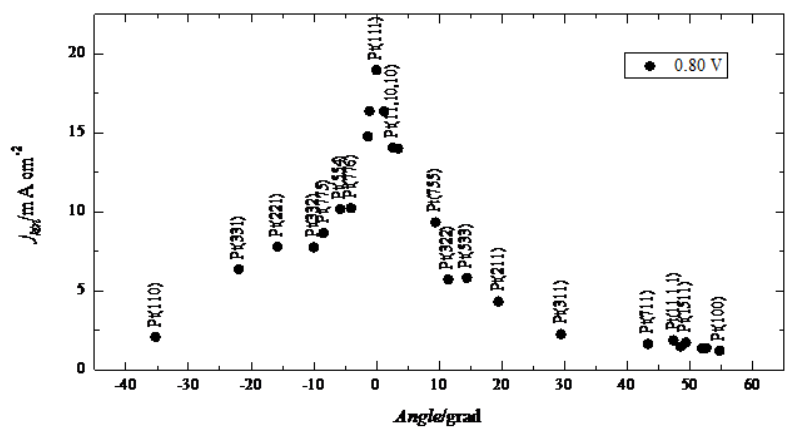

Fig. 4. Plot of the kinetic current measured at $0.80 \mathrm{~V}$ for the different electrodes vs. the angle of the surface normal with respect to the (111) 10 direction.

Additionally, the positive slope obtained for the surfaces with (100) terraces and (111) steps indicates that the electrocatalytic activity of those steps is slightly higher than that of the terrace. On the other hand, for the (100) and (110) steps on the (111) 15 terraces, the activity of the steps is much lower than that of the terrace. In fact, the linear regressions for those surfaces cut the abscissas axis at step densities corresponding to the $\operatorname{Pt}(221)$ and $\mathrm{Pt}(211)$ surfaces. These surfaces have 2-atom wide (111) terraces and a monoatomic (110) or (100) step, respectively. This means 20 that the activity of the steps is negligible with respect to that measured for the terrace, that is, the observed electrocatalytic activity for those surfaces can be almost exclusively related to the terrace sites. Thus, the electrocatalytic activity of the steps on the (111) terrace in alkaline solutions differs significantly from that 25 observed in acidic solutions.

From the different activity found in perchloric and sulfuric acid solutions, it is clear that the adsorbed species play a significant role in the reactivity. ${ }^{11,12}$ Thus, the lower activity measured in sulfuric acid solution is related to the strong sulfate adsorption on 30 the electrode surface. Also, the lower activity observed for the $\mathrm{Pt}(100)$ electrode in perchloric acid solution with respect to that of the $\mathrm{Pt}(111)$ electrode has been associated with the stronger $\mathrm{OH}$ interaction with the surface for the $\operatorname{Pt}(100)$ electrode. ${ }^{50}$ In that sense, the higher activity of the $\mathrm{Pt}(111)$ electrode is also observed 35 in alkaline media, and it can also be related to the differences in the $\mathrm{OH}$ adsorption energy. As has been already discussed, the shape of the voltammograms for the $\operatorname{Pt}(100)$ and $\operatorname{Pt}(111)$ electrodes in perchloric acid and alkaline electrolytes is different. However, the potential regions where $\mathrm{OH}$ adsorption takes place 40 in both media are the same in the RHE scale, which necessarily implies that the energy for adsorption of $\mathrm{OH}$ species is very similar. Thus, the difference in the activity at $0.8 \mathrm{~V}$ between the $\mathrm{Pt}(111)$ and $\mathrm{Pt}(100)$ in both media is very similar, ca. one order of magnitude, since the differences in $\mathrm{OH}$ adsorption strength for ${ }_{45}$ these electrodes do not depend on the $\mathrm{pH}$.
Regarding the effect of the steps, $\mathrm{OH}$ adsorption on the (111) steps present on (100) terraces takes place at potentials similar to the adsorption on the (100) terrace. ${ }^{34}$ Thus, the current densities measured for the ORR should not be affected by the $\mathrm{OH}$ 50 adsorption strength. Other effects, such as the interaction energy of oxygen with the site, should then determine the small increase of the calculated kinetic current, and probably in this case, it is responsible for the small catalytic increase as the step are introduced on the (100) plane.

55
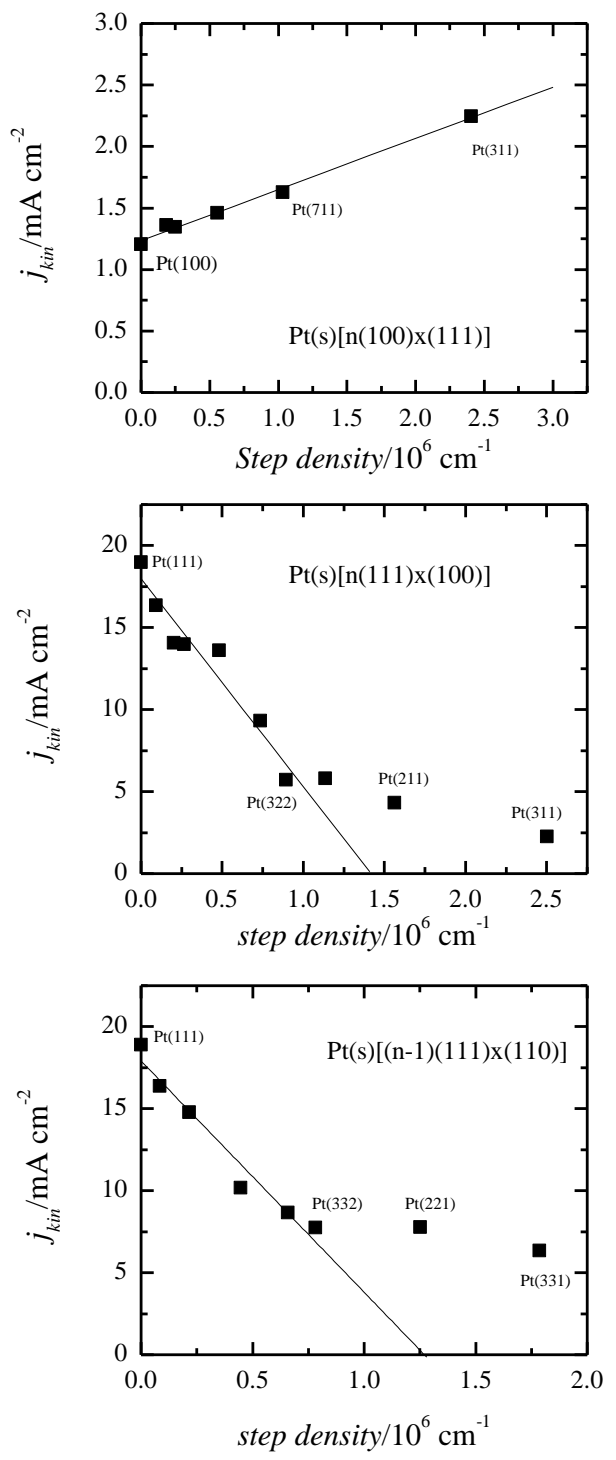

Fig. 5. Plot of the kinetic current measured at $0.8 \mathrm{~V}$ for the different electrodes in the series of stepped surfaces vs. the step density. The line represents the linear fit obtained with de data with low step densities.

${ }_{60}$ On the other hand, $\mathrm{OH} / \mathrm{O}$ adsorption on the (110) or the (100) steps present on the (111) terrace occurs at much more negative potentials. Assuming that the peak in the voltammograms for those steps contains contributions related to the $\mathrm{OH} / \mathrm{O}$ adsorption on those sites, the onset for $\mathrm{OH} / \mathrm{O}$ adsorption is 0.26 and $0.40 \mathrm{~V}$ 
for the (110) and (100) steps, respectively. Thus, there is a large difference between $\mathrm{OH}$ adsorption on the (111) terrace and that on the steps. This potential difference implies that the adsorption energy of $\mathrm{OH}$ on the steps is much larger than that on the terrace 5 and then, the activity of the step for the ORR is negligible when compared to that measured for the terrace.

The major problem with the previous interpretation is that similar results should have been obtained in perchloric acid. As aforementioned, the activity of the steps in the (111) terraces is

10 higher in perchloric acid solutions, and the different in the adsorption energy for $\mathrm{OH}$ between the (111) and the steps is even larger in acid media. However, the activity of the step sites in acid media is larger than that of the (111) terrace sites, unlike the behavior observed in alkaline media. The origin of these 15 differences is not clear and deserves further and detailed study. However, it may be related i) to a different ratio of adsorbed $\mathrm{OH} / \mathrm{O}$ on the step, as has been proposed, ${ }^{24}$ which in turns affects the whole reaction mechanism, ii) to a different water structure with the $\mathrm{pH}$ or iii) to effects related to the different electrode 20 charge, since the absolute electrode potential is significantly different. In fact, $\mathrm{pH}$ effects have been detected for the rate of water reorganization on platinum electrodes ${ }^{29}$ Also, the different reactivity of adsorbed $\mathrm{CO}$ on stepped platinum surfaces in acidic and alkaline media have been attributed to the different electrode

${ }^{25}$ charge in the two media. ${ }^{51}$ All of these results suggest that these types of effects have to be taken into consideration if the differences between alkaline and acidic media have to be understood.

\section{Analysis of the mechanism of the ORR in $0.1 \mathrm{M} \mathrm{NaOH}$.}

From the results shown in figure 3 , it is clear that two different linear Tafel regions exist in the curves. The Tafel slope values in the region at high potentials, that is, between 1.00 and $0.82 \mathrm{~V}$ are $70 \pm 5 \mathrm{mV}$ for the surfaces vicinal to the (111) pole and $95 \pm 6 \mathrm{mV}$ 35 for the surfaces with (100) terraces, in agreement with previous results for basal planes. ${ }^{8}$ At lower potentials, the Tafel slope values increase significantly reaching values close to $200 \mathrm{mV}$ for the surfaces vicinal to the (100) pole or even higher for the stepped surfaces with (111) terraces. The Tafel slopes values 40 below $130 \mathrm{mV}$ can be easily justified by considering different mechanisms. However, larger Tafel slopes clearly indicate the existence of an inhibition mechanism that counteracts the effect of the electrode potential in the variation of the kinetic constant.

Before analyzing the results, it should be discarded the presence 45 of some artifact in the measurements that could lead to such high Tafel slope values. First of all, although the measurements were carried out without $\mathrm{iR}$ drop compensation, it was checked that the correction of the $\mathrm{iR}$ drop lead to the same reduction currents. Secondly, the error in the determination of the kinetic current 50 increases significantly when the current approaches the limiting current. For the $\operatorname{Pt}(111)$ electrode, the limiting current is ca. -7.6 $\mathrm{mA} \mathrm{cm}{ }^{-2}$, whereas the current at $0.82 \mathrm{~V}$, the potential at which the high Tavel slope value is obtained, is $-5.0 \mathrm{~mA} \mathrm{~cm}$, ca. $65 \%$ of the limiting current. For this current value, the procedure for 55 obtaining the kinetic current does not give significant error that could justify the change in the Tafel slope. In fact, it could be demonstrated that for a process in which the Tafel slope is ca. 70$90 \mathrm{mV}$ in the whole potential range the limiting current should be measured at $0.8 \mathrm{~V}$, in the region between $0.4-0.8 \mathrm{~V}$. The 60 situation is even more clear for the $\mathrm{Pt}(100)$ electrode. The current at 0.82 is $-0.7 \mathrm{~mA} \mathrm{~cm}^{-2}$ for a limiting current of ca. $8 \mathrm{~mA} \mathrm{~cm}$. Under those circumstances, the error in the calculation of kinetic currents using eq. (4) is negligible.

In order to get insight into the mechanism of the ORR using the 65 Tafel slopes, the effect of the $\mathrm{OH}$ coverage has to be taken into account. It has been proposed that the active sites for the ORR are those not covered by $\mathrm{OH}$ and also that there is a strong repulsion between the $\mathrm{OH}$ and the $\mathrm{O}_{2}$ molecules on the interface. ${ }^{10}$ Thus, the kinetic equation can be written as:

$70 \quad j_{k i n}=4 F k\left(\theta_{O H, \max }-\theta_{O H}\right) c_{O_{2}} \exp \left(-\alpha \frac{F E}{R T}\right) \exp \left(-\gamma \theta_{O H}\right)$

where $k$ is the kinetic rate constant, which depends on the electrode potential, $\theta_{\mathrm{OH}}$ and $\theta_{\mathrm{OH} \text {,max }}$ are the $\mathrm{OH}$ coverage and the maximum $\mathrm{OH}$ coverage, respectively, $\alpha$ is the transfer coefficient for the reaction and $\gamma$ is the interaction parameter of the $\mathrm{O}_{2}$ 75 molecule with the adsorbed $\mathrm{OH}$. For such equation the Tafel slope is defined as:

$$
\begin{aligned}
m_{\text {Tafel }} & =\frac{1}{\frac{\frac{\partial \log (j)}{\partial E} \mid}{\partial E}=} \\
& =\mid \frac{1}{\frac{\partial \log \left(\theta_{O H, \text { max }}-\theta_{O H}\right)}{\partial E}-\frac{\alpha F}{R T \ln (10)}-\gamma \frac{\partial \theta_{O H}}{\ln (10) \partial E} \mid}
\end{aligned}
$$

The analysis of this equation and the effects in the Tafel slope values should be carried using the $\mathrm{OH}$ coverage changes in the 80 electrode. Recent results using electrochemical impedance spectroscopy indicates that the adsorption of $\mathrm{OH}$ on $\mathrm{Pt}(111)$ electrodes is not affected by the ORR. ${ }^{52}$ Thus, the blank voltammetry in $0.1 \mathrm{M} \mathrm{NaOH}$ can be used to detect the variations of the $\mathrm{OH}$ coverage. For the $\mathrm{Pt}(111)$ electrode, $\mathrm{OH}$ adsorption 85 takes place between 0.6 and ca. $0.82 \mathrm{~V}$. Below $0.6 \mathrm{~V}$ the $\mathrm{OH}$ coverage can be considered negligible and above $0.82 \mathrm{~V}$, the $\mathrm{OH}$ coverage has reached a saturation value, and it is independent of the potential up to $1.1 \mathrm{~V}$. Thus, between 0.82 and $1 \mathrm{~V}$, the terms $\frac{\partial \log \left(\theta_{O H, \max }-\theta_{O H}\right)}{\partial E}$ and $-\gamma \frac{\partial \theta_{O H}}{\ln (10) \partial E}$ are zero and the expression 90 for the Tafel slope is then:

$$
m_{\text {Tafel }}=\left|\frac{1}{-\frac{R T \ln (10)}{\alpha F}}\right|
$$

This type of equation can describe the observed behavior between 0.82 and $1.00 \mathrm{~V}$. However, at potentials below $0.82 \mathrm{~V}$, the terms associated to the $\mathrm{OH}$ coverage change are negative, since the $\mathrm{OH}$ ${ }_{95}$ coverage increases with the electrode potential. In fact, all the terms in the denominator of eq. (6) are negative, so that the denominator in this potential region is, in absolute value, larger than that measured above $0.82 \mathrm{~V}$ and this should lead to a diminution in the Tafel slope value. However, the opposite 
behavior is observed; between 0.6 and $0.82 \mathrm{~V}$, the Tafel slope is larger than that measured above $0.82 \mathrm{~V}$. In fact, if adsorbed $\mathrm{OH}$ is an intermediate in the reaction, it does not seem logical that the fraction of the surface covered by the $\mathrm{OH}$ is not participating in 5 the reaction. A similar situation is observed for the $\operatorname{Pt}(100)$ electrode. The $\mathrm{OH}$ adsorption starts at potentials ca. $0.4 \mathrm{~V}$ and a saturation value is obtained at ca. $0.7 \mathrm{~V}$, although some small changes between 0.7 and $0.8 \mathrm{~V}$ cannot be discarded because some residual currents are measured in the voltammogram. In this 10 sense, a similar behavior than that described for the $\operatorname{Pt}(111)$ electrode should be expected, as has been found in figure 3 .

It is clear that this previous model is not able to reproduce the observed behavior at potentials below $0.82 \mathrm{~V}$. In this model, adsorbed $\mathrm{OH}$ is considered as a poison, however, all the DFT 15 models consider adsorbed $\mathrm{OH}$ as an intermediate of the reaction. ${ }^{53-56}$ Additionally, the $\mathrm{OH}$ coverage is very high at the upper potential limit for all the studied electrodes, and the number of free sites would be negligible. If the free sites were the only sites contributing to the ORR, their intrinsic activity of these 20 sites would be unprecedentedly high. To propose a kinetic equation that is in agreement with the experimental results, the fraction of the surface covered by $\mathrm{OH}$ has to be considered and included explicitly in the equation. Thus, the kinetic equation is then:

25

$$
j_{k i n}=4 F k \theta_{O H} c_{O_{2}} \exp \left(-\alpha \frac{F E}{R T}\right)
$$

In this expression, the part of the surface covered by $\mathrm{OH}$ is active for the reaction. Then, the Tafel slope can be calculated as:

$$
m_{\text {Tafel }}=\frac{1}{\left|\frac{\partial \log (j)}{\partial E}\right|}=\left|\frac{1}{\frac{\partial \log \left(\theta_{O H}\right)}{\partial E}-\frac{\alpha F}{R T \ln (10)}}\right|
$$

As before, above $0.82 \mathrm{~V}$, where the $\mathrm{OH}$ coverage is constant, the 30 term $\frac{\partial \log \left(\theta_{O H}\right)}{\partial E}$ is zero and the Tafel slope follows equation (7).

At more negative potentials, the diminution of the $\mathrm{OH}$ coverage for the Pt(111) electrode below should lead to an increase in the value of the Tafel slope, since the term corresponding to the variation of the coverage with the potential is positive, in 35 agreement with the experimental results. An additional support for the model presented in equation (9) is obtained from the results of the $\mathrm{Pt}(100)$ electrode. For this latter case, the change of $\mathrm{OH}$ coverage in this region is much smaller in comparison with that of the $\operatorname{Pt}(111)$ electrode, which also explains why the Tafel 40 slope is smaller for this electrode. All these results indicate that the electron transfer reaction should come from the $\mathrm{OH}$ covered sites, especially in the high potential region. However, the contribution of the surface not covered by $\mathrm{OH}$ cannot be discarded at low potentials. When the $\mathrm{OH}$ coverage is zero for the ${ }_{45} \mathrm{Pt}(111)$ electrode, at potentials negative to $0.6 \mathrm{~V}$, the activity for the ORR is almost maintained. In this potential region, the diminution in the activity due to the disappearance of the $\mathrm{OH}$ covered sites is compensated by the increasing activity of the free sites as the overpotential is made more negative.
50 A complementary explanation to the high Tafel slope values obtained at high overpotentials is the accumulation of intermediates on the surface. A detailed DFT study has shown that adsorbed water or $\mathrm{OH}$ can accumulate on the $\operatorname{Pt}(111)$ electrode at high overpotentials during the ORR, because the rate 55 of formation is much higher than the rate of desorption or further oxidation to water. ${ }^{52,53}$ In this is true, the accumulation of these species leads to apparent constant rates which are almost independent of the electrode potential, as experimentally observed above $0.75 \mathrm{~V}$. Anyhow, both explanations reinforce the 60 role of the adsorbed $\mathrm{OH}$ in the ORR mechanism. This species cannot be considered as a mere spectator of the reaction, which only prevents the adsorption of oxygen on the electrode surface. On the contrary, it seems clear that the $\mathrm{OH}$ adsorption strength and its final oxidation to water are key elements to understand the 65 oxidation mechanism.

The results presented here are in excellent qualitative agreement with the results from DFT calculations presented in reference ${ }^{53}$, which relates the reaction rates to the difference in the rates of formation and desorption of the intermediate species. The onset 70 for the ORR on the Pt (111) electrode is the highest, because at 0.9 the formation rate of adsorbed $\mathrm{OH}$ is similar to that of the desorption process. On the other hand, since the adsorption strength of $\mathrm{OH}$ on the $\mathrm{Pt}(100)$ electrode or the steps is higher, the rate of oxidation is smaller. It should be stressed that this 75 correlation is not found in acid media, which suggest that the simulation conditions are closer to that observed experimentally in alkaline solutions than those corresponding to acid solutions.

\section{Conclusions}

${ }_{80}$ The results presented here clearly shows that the electrode surface with the highest activity for the ORR in alkaline media is the $\mathrm{Pt}(111)$ electrode. On the perfect $\mathrm{Pt}(111)$ electrode, the addition of defects leads to a significant diminution of the electrocatalytic activity for the reaction. The extrapolation of the results obtained 85 with surfaces with long (111) terraces indicates that the activity of the steps is negligible in comparison with that measured for the (111) terrace. Also, the kinetic analysis of the data and the comparison with acidic media leads to the conclusion that the adsorbed $\mathrm{OH}$ is a key species in the oxidation mechanism and it 90 is not a mere spectator blocking adsorption sites for oxygen adsorption. The adsorption strength and other factors as the interaction with the water, the water structure and the $\mathrm{pH}$ determines the overall reaction rate for the ORR.

\section{${ }_{95}$ Acknowledgments}

This work has been financially supported by the MICINN (Spain) (project CTQ2010-16271-FEDER) and Generalitat Valenciana (project PROMETEO/2009/045, -FEDER).

\section{References}

100 1. N. M. Markovic and P. N. Ross, Surf. Sci. Rep., 2002, 45, 117-229. 
2. A. Schneider, L. Colmenares, Y. E. Seidel, Z. Jusys, B. Wickman, B. Kasemo and R. J. Behm, Phys. Chem. Chem. Phys., 2008, 10, 1931-1943.

3. N. M. Markovic, H. A. Gasteiger and P. N. Ross, J. Phys. Chem., 1995, 99, 3411-3415.

4. N. M. Markovic, H. A. Gasteiger and N. Philip, J. Phys. Chem. B, 1996, 100, 6715-6721.

5. B. N. Grgur, N. M. Markovic and P. N. Ross, Can. J. Chem., 1997, 75, 1465-1471.

106 V. Stamenkovic, N. M.Markovic and P. N. RossJr, J. Electroanal. Chem., 2001, 500, 44-51.

7. V. Stamenkovic, T. J. Schmidt, P. N. Ross and N. M. Markovic, J. Phys. Chem. B, 2002, 106, 11970-11979.

8. T. J. Schmidt, V. Stamenkovic, P. N. Ross and N. M. Markovic,

15 Phys. Chem. Chem. Phys., 2003, 5, 400-406.

9. C. Wang, N. M. Markovic and V. R. Stamenkovic, ACS Catal., 2012, 2, 891-898.

10. J. X. Wang, N. M. Markovic and R. R. Adzic, J. Phys. Chem. B, 2004, 108, 4127-4133.

20 11. M. D. Maciá, J. M. Campina, E. Herrero and J. M. Feliu, J. Electroanal. Chem., 2004, 564, 141-150.

12. A. Kuzume, E. Herrero and J. M. Feliu, J. Electroanal. Chem., 2007, 599, 333-343.

13. U. A. Paulus, A. Wokaun, G. G. Scherer, T. J. Schmidt, V. 25 Stamenkovic, N. M. Markovic and P. N. Ross, Electrochim. Acta, 2002, 47, 3787-3798.

14. C. M. Sanchez-Sanchez, J. Solla-Gullon, F. J. Vidal-Iglesias, A. Aldaz, V. Montiel and E. Herrero, J. Am. Chem. Soc., 2010, 132, 5622-5624.

30 15. T. J. Schmidt, V. Stamenkovic, M. Arenz, N. M. Markovic and J. P. N. Ross, Electrochim. Acta, 2002, 47, 3765-3776.

16. N. M. Marković, R. R. Adžić, B. D. Cahan and E. B. Yeager, J. Electroanal. Chem., 1994, 377, 249-259.

17. J. Clavilier, D. Armand, S. G. Sun and M. Petit, J. Electroanal. 35 Chem., 1986, 205, 267-277.

18. E. Herrero, J. M. Orts, A. Aldaz and J. M. Feliu, Surf. Sci., 1999, 440, 259-270.

19. N. Garcia-Araez, V. Climent, E. Herrero and J. M. Feliu, Surf. Sci., 2004, 560, 269-284.

40 20. B. Lang, R. W. Joyner and G. A. Somorjai, Surf. Sci., 1972, 30, 454474.

21. R. Subbaraman, N. Danilovic, P. P. Lopes, D. Tripkovic, D. Strmcnik, V. R. Stamenkovic and N. M. Markovic, J. Phys. Chem. c, 2012, 116, 22231-22237.

45 22. A. S. Bondarenko, I. E. L. Stephens, H. A. Hansen, F. J. PérezAlonso, V. Tripkovic, T. P. Johansson, J. Rossmeisl, J. K. Nørskov and I. Chorkendorff, Langmuir, 2011, 27, 2058-2066.

23. A. Berna, V. Climent and J. M. Feliu, Electrochem. Commun., 2007, 9, 2789-2794.

50 24. M. J. T. C. van der Niet, N. Garcia-Araez, J. Hernández, J. M. Feliu and M. T. M. Koper, Catal. Today, 2013, 202, 105-113.

25. K. J. P. Schouten, M. van der Niet and M. T. M. Koper, Phys. Chem. Chem. Phys., 2010, 12, 15217-15224.

26. M. van der Niet, O. T. Berg, L. B. F. Juurlink and M. T. M. Koper, J.

55 Phys. Chem. C, 2010, 114, 18953-18960.

27. O. Y. Samoilov, Discussions of the Faraday Society, 1957, 141-146.
28. H. S. Frank and W. Wen, Discussions of the Faraday Society, 1957, 24, 133-140.

29. N. Garcia-Araez, V. Climent and J. M. Feliu, Electrochim. Acta, 2009, 54, 966-977.

30. V. Climent, G. A. Attard and J. M. Feliu, J. Electroanal. Chem., 2002, 532, 67-74.

31. G. A. Attard, O. Hazzazi, P. B. Wells, V. Climent, E. Herrero and J. M. Feliu, J. Electroanal. Chem., 2004, 568, 329-342.

65 32. T. Pajkossy and D. M. Kolb, Electrochim. Acta, 2001, 46, $3063-$ 3071.

33. Z. Kerner, T. Pajkossy, L. A. Kibler and D. M. Kolb, Electrochem. Commun., 2002, 4, 787-789.

34. R. M. Arán-Ais, M. C. Figueiredo, F. J. Vidal-Iglesias, V. Climent, 70 E. Herrero and J. M. Feliu, Electrochim. Acta, 2011, 58, 184192.

35. M. Wakisaka, Y. Udagawa, H. Suzuki, H. Uchida and M. Watanabe, Energy Environ. Sci., 2011, 4, 1662-1666.

36. H. M. Villullas and M. L. Teijelo, J. Electroanal. Chem., 1995, 384, 75 25-30.

37. H. M. Villullas and M. L. Teijelo, J. Electroanal. Chem., 1995, 385, $39-44$.

38. R. Smoluchowski, Physical Review, 1941, 60, 661-674.

39. J. Lecoeur, J. Andro and R. Parsons, Surf. Sci., 1982, 114, 320-330.

80 40. G. L. Beltramo, H. Ibach and M. Giesen, Surf. Sci., 2007, 601, 18761885.

41. V. Grozovski, V. Climent, E. Herrero and J. M. Feliu, ChemPhysChem, 2009, 10, 1922-1926.

42. V. Grozovski, V. Climent, E. Herrero and J. M. Feliu, J. Electroanal. 85 Chem., 2011, 662, 43-51.

43. N. P. Lebedeva, M. T. M. Koper, J. M. Feliu and R. A. van Santen, J. Phys. Chem. B, 2002, 106, 12938-12947.

44. V. Grozovski, V. Climent, E. Herrero and J. M. Feliu, Phys. Chem. Chem. Phys., 2010, 12, 8822-8831.

90 45. L. J. Buller, E. Herrero, R. Gómez, J. M. Feliu and H. D. Abruna, Journal of the Chemical Society-Faraday Transactions, 1996, 92, 3757-3762.

46. E. Herrero, V. Climent and J. M. Feliu, Electrochem. Commun., 2000, 2, 636-640.

95 47. R. Francke, V. Climent, H. Baltruschat and J. M. Feliu, J. Electroanal. Chem., 2008, 624, 228-240.

48. K. B. Besocke, B. Krahl-Urban and H. Wagner, Surf. Sci., 1977, 68, 39-46.

49. R. Gómez, V. Climent, J. M. Feliu and M. J. Weaver, J. Phys. Chem. $100 \quad B, 2000,104,597-605$.

50. B. Han, V. Viswanathan and H. Pitsch, J. Phys. Chem. c, 2012, 116, 6174-6183.

51. E. Herrero, Q.-S. Chen, J. Hernandez, S.-G. Sun and J. M. Feliu, Phys. Chem. Chem. Phys., 2011, 13, 16762-16771.

105 52. A. S. Bondarenko, I. E. L. Stephens, H. A. Hansen, F. J. PerezAlonso, V. Tripkovic, T. P. Johansson, J. Rossmeisl, J. K. Norskov and I. Chorkendorff, Langmuir, 2011, 27, 2058-2066.

53. J. A. Keith and T. Jacob, Angew. Chem. Int. Edit., 2010, 49, 95219525.

110 54. M. T. M. Koper, Nanoscale, 2011, 3, 2054-2073. 
55. V. Stamenkovic, B. S. Mun, K. J. J. Mayrhofer, P. N. Ross, N. M. Markovic, J. Rossmeisl, J. Greeley and J. K. N ${ }^{\circ}$ rskov, Angew. Chem. Int. Edit., 2006, 45, 2897-2901.

56. J. Greeley, J. Rossmeisl, A. Hellman and J. K. Nørskov, Z. Phys. Chem. (Muenchen, Ger.), 2007, 221, 1209-1220. 